\title{
An unsere Leser
}

Von September 1944 bis Dezember 1945 sind zwei Bände zu vier Heften unserer Zeitschrift erschíenen. In diesem verhältnísmäßíg kurzen Zeítraum hat sích die Zeítschríft eínen großen Freundeskreís erwerben können, was sich sowohl in der Zahl der Abonnenten wíe vor allem auch in der Zahl der eíngehenden Arbeiten deutlích ausdrückt. Nachdem sích erwíesen hat, daß bisher schon jeden zweíten Monat eín Heft herausgebracht werden mußte und die Zahl der vorlíegenden Manuskrípte ständíg ansteígt, sahen sích Redaktion und Verlag vor die Frage gestellt, ob das ursprünglíche Programm mít vier Heften pro Jahr noch genügend seín werde, oder ob nícht die Vermehrung der Zeítschríft auf sechs Hefte jährlích angezeígt ware. Es ist Mar, daß es unmöglich seín würde, die eíngehenden Manuskripte auch nur an-nähernd in nützlícher Frist zu publizieren, und daß daher die Zeitschrift den so erfreulíchen Aufstieg wahrscheínlich nícht beíbehalten würde, wenn man sie in ihrem Umfang gewaltsam auf der ursprüng lichen, noch während des Kríeges vorgesehenen Basis festlegen würde. Wir haben uns daher entschlossen, von Vol 3, 1946, an jährlích sechs Hefte zu publizieren. Dementsprechend mußte auch der Abonnements-preís von Fr. 24.- auf Fr. 36.- heraufgesetzt werden. Die Abonnenten werden jedoch noch weit mehr erhalten, weil die Zeítschríft in ihrem Umfang über das Maß von sechs normalen Heften hínaus erweítert werden wírd, und in diesem Jahr jedenfalls noch eín Supplementheft kostenlos hinzugefügt wírd. Wir hoffen, daß auch unsere Abonnenten sích mit dieser Maß̈̈ïahme einverstanden erklären und werden uns freuen, wenn die Zufríedenheít mit der Lösung der zu erfüllenden Aufgaben auch weíterhin durch die Zuführung neuer Abonnenten und Mit-arbeíter zum Ausdruck gebracht wird.

Die Redaktionskommission. 